Published in final edited form as:

Environ Int. 2016 May ; 91: 104-115. doi:10.1016/j.envint.2016.02.014.

\title{
Military Service, Deployments, and Exposures in Relation to Amyotrophic Lateral Sclerosis Etiology
}

\author{
John D. Beard ${ }^{a, b}, 1$, Lawrence S. Engel ${ }^{a}$, David B. Richardson ${ }^{a}$, Marilie D. Gammon ${ }^{a}$, Coleen \\ Baird $^{\text {C }}$, David M. Umbach ${ }^{d}$, Kelli D. Allen ${ }^{e, f}$, Catherine L. Stanwyck ${ }^{e, g}$, Jean Keller ${ }^{h}$, Dale P. \\ Sandler ${ }^{\mathrm{b}}$, Silke Schmidt ${ }^{\mathrm{g}}$, and Freya Kamel ${ }^{\mathrm{b},{ }^{*}}$ \\ aDepartment of Epidemiology, Gillings School of Global Public Health, University of North \\ Carolina at Chapel Hill, Chapel Hill, North Carolina, USA \\ bEpidemiology Branch, National Institute of Environmental Health Sciences, Research Triangle \\ Park, North Carolina, USA \\ 'Environmental Medicine Program, US Army Public Health Command, Aberdeen Proving Ground, \\ Maryland, USA \\ dBiostatistics and Computational Biology Branch, National Institute of Environmental Health \\ Sciences, Research Triangle Park, North Carolina, USA \\ eDurham VA Medical Center, Durham, North Carolina, USA \\ fDepartment of Medicine and Thurston Arthritis Research Center, University of North Carolina at \\ Chapel Hill, Chapel Hill, North Carolina, USA \\ gDepartment of Medicine, Duke University Medical Center, Durham, North Carolina, USA \\ hWestat, Inc., Durham, North Carolina, USA
}

\begin{abstract}
Background-Factors underlying a possible excess of amyotrophic lateral sclerosis (ALS) among military veterans remain unidentified. Limitations of previous studies on this topic include reliance on ALS mortality as a surrogate for ALS incidence, low statistical power, and sparse information on military-related factors.
\end{abstract}

Objectives-We evaluated associations between military-related factors and ALS using data from a case-control study of U.S. military veterans.

\footnotetext{
*Corresponding author at: Epidemiology Branch, National Institute of Environmental Health Sciences, 111 T.W. Alexander Dr., A3-05, Research Triangle Park, NC 27709 USA. Telephone: + 1919541 1581. Fax: + 1301480 3290. ; Email: kamel@niehs.nih.gov (F. Kamel).

1 Present address: Industrywide Studies Branch, Division of Surveillance, Hazard Evaluations, and Field Studies, National Institute for Occupational Safety and Health, Cincinnati, Ohio, USA

Publisher's Disclaimer: This is a PDF file of an unedited manuscript that has been accepted for publication. As a service to our customers we are providing this early version of the manuscript. The manuscript will undergo copyediting, typesetting, and review of the resulting proof before it is published in its final citable form. Please note that during the production process errors may be discovered which could affect the content, and all legal disclaimers that apply to the journal pertain.

Conflict of interest

The authors declare they have no competing financial interests.
} 
Methods-From 2005 to 2010, we identified medical record-confirmed ALS cases via the National Registry of Veterans with ALS and controls via the Veterans Benefits Administration's Beneficiary Identification and Records Locator System database. In total, we enrolled 621 cases and 958 frequency-matched controls in the Genes and Environmental Exposures in Veterans with Amyotrophic Lateral Sclerosis study. We collected information on military service and deployments and 39 related exposures. We used unconditional logistic regression models to estimate odds ratios (ORs) and 95\% confidence intervals (CIs). We used inverse probability weighting to adjust for potential bias from confounding, missing covariate data, and selection arising from a case group that disproportionately included long-term survivors and a control group that may or may not differ from U.S. military veterans at large.

Results-The odds of ALS did not differ for veterans of the Air Force, Army, Marines, and Navy. We found higher odds of ALS for veterans whose longest deployment was World War II or the Korean War and a positive trend with total years of all deployments (OR $=1.27 ; 95 \%$ CI: 1.06 , 1.52). ALS was positively associated with exposure to herbicides for military purposes, nasopharyngeal radium, personal pesticides, exhaust from heaters or generators, high-intensity radar waves, contaminated food, explosions within one mile, herbicides in the field, mixing and application of burning agents, burning agents in the field, and Agent Orange in the field, with ORs between 1.50 and 7.75 .

Conclusions-Although our results need confirmation, they are potentially important given the large number of U.S. military veterans, and they provide clues to potential factors underlying the apparent increase of ALS in veteran populations.

\section{Keywords}

amyotrophic lateral sclerosis; case-control; deployment; etiology; military

\section{Introduction}

Amyotrophic lateral sclerosis (ALS) is a debilitating neurodegenerative disease involving motor neuron loss in the central nervous system (Mitchell and Borasio, 2007). A possible association between military-related factors and ALS was first suggested in connection with the 1990-1991 Persian Gulf War (hereafter "Gulf War"). Five of seven previously published studies reported an increased rate of ALS incidence, hospitalization, or mortality among veterans deployed to the Gulf War compared to veterans deployed elsewhere (Barth et al., 2009; Coffman et al., 2005; Haley, 2003; Horner et al., 2008; Horner et al., 2003; Kang and Bullman, 2001; Smith et al., 2000). Another study found a higher ALS mortality rate among men who reported military service than men who did not (Weisskopf et al., 2005). This result was recently confirmed by studies in the U.S. (Weisskopf et al., 2015), Denmark (Seals et al., 2015), and Scotland (Bergman et al., 2015). Most of these studies, and 22 others on this topic that we recently reviewed (Beard and Kamel, 2015), were limited by reliance on ALS mortality as a surrogate for ALS incidence, low statistical power, and sparse information on military-related factors. In addition, two-thirds of these studies did not include information on specific military exposures. Thus, the factors underlying the possibly increased rate of ALS among veterans remain unidentified. 
The Genes and Environmental Exposures in Veterans with Amyotrophic Lateral Sclerosis study (GENEVA), conducted from 2005 to 2010, is a case-control study of veterans with ALS from the U.S. National Registry of Veterans with ALS (hereafter "Registry") (Allen et al., 2008) and frequency-matched veteran controls identified via U.S. Department of Veterans Affairs (VA) databases (Schmidt et al., 2008). To enroll in GENEVA, participants had to confirm that they had been members of the U.S. Army, Air Force, Navy, Marine Corps, Coast Guard, activated Reserves or National Guard at some point in time (Beard, 2015). They did not have to have been deployed to war. We evaluated associations between ALS and several aspects of military service and deployments as well as 39 related exposures among veterans in GENEVA.

\section{Materials and methods}

\subsection{Study population and case definition}

Enrollment of cases first in the Registry, then in GENEVA, was described previously (Allen et al., 2008; Schmidt et al., 2008). Briefly, the Registry was started because of the possible connection between ALS and deployment to the Gulf War (Allen et al., 2008; Kasarskis et al., 2004; Schmidt et al., 2008). Potential cases were recruited for the Registry from 2003 to 2007 (i.e., the year Haley (2003) and Horner (2003) were published to when funding expired). Recruitment strategies included publicizing the Registry and searches of national VA databases for patients with International Classification of Diseases, 9th Revision (World Health Organization, 1977), codes of the form 335.2X (motor neuron diseases) (Allen et al., 2008). In total, 7,116 potential cases were identified, 4,626 completed a telephone screening (Beard, 2015), and 2,600 reported a past diagnosis (Allen et al., 2008). Of these, 2,400 consented to join, 2,265 provided medical records for review by ALS specialist neurologists, and 2,122 had a diagnosis of ALS or a related motor neuron disease confirmed according to the Revised El Escorial Criteria (Allen et al., 2008; Brooks et al., 2000). These 2,122 veteran cases were followed via standardized semi-annual telephone interviews until 2009.

Ascertainment of GENEVA cases from those enrolled in the Registry is shown in Figure 1. Of 1,856 ALS cases, 1,837 gave permission to be re-contacted for further studies, 1,356 consented to join the Registry DNA bank, and 847 were able to be contacted regarding GENEVA enrollment. Of these, 726 consented to join and 630 were interviewed of which 621 were included in this analysis because they were not missing covariate data. These cases include those with clinically definite, probable, possible, or suspected ALS.

Enrollment of GENEVA controls was described previously (Schmidt et al., 2008). Figure 2 shows ascertainment of GENEVA controls from an age-stratified random sample of 10,000 records obtained in June 2005 from the Veterans Benefits Administration's Beneficiary Identification and Records Locator System (BIRLS) database (Schmidt et al., 2008). Of 8,966 potential controls with addresses available, 4,420 were mailed invitations, 2,728 were able to be contacted by telephone, and 1,618 were screened for eligibility. Nine individuals not part of the original BIRLS sample contacted GENEVA regarding enrollment and were screened for eligibility. In total, 1,536 potential controls were eligible, 1,055 consented to join, and 975 controls were interviewed of which 958 were included in this analysis because they were not missing covariate data. 
Controls were frequency-matched to cases on diagnosis age (within five years) and use of the VA health care system before diagnosis date (cases) or interview date (controls) (Schmidt et al., 2008). We matched on age because it is a risk factor for ALS (Mitchell and Borasio, 2007). VA health care use served as a surrogate for socioeconomic status, which may be related to ALS (Sutedja et al., 2007).

GENEVA was approved by Institutional Review Boards of the Durham VA Medical Center, Duke University Medical Center, and the National Institute of Environmental Health Sciences; the Institutional Review Board of the University of North Carolina at Chapel Hill approved this ancillary study. All participants gave written or oral informed consent before enrollment.

\subsection{Exposure assessment}

For cases, we extracted clinical characteristics from medical records and collected baseline (closest to GENEVA enrollment) ALS Functional Rating Scale-Revised (ALSFRS-R) score (Cedarbaum et al., 1999) via the Registry semi-annual interviews (Beard, 2015). For cases and controls, we used standardized telephone interviews for GENEVA (Beard, 2015) to gather information on military service, deployments, and exposures that occurred before diagnosis date (cases) or interview date (controls), as well as on potential confounders (Beard, 2015; Schmidt et al., 2008). Proxy interviews were necessary for 34 (5\%) cases, but no controls. More detail regarding interview procedures is provided elsewhere (Schmidt et al., 2008).

Self-reported information on military service included branch of longest service (i.e., the branch in which the veteran served the longest total time), number of branches, rank, total service time, and end of most recent service (Supplementary data, p. S3). Self-reported information on deployments to World War II (WWII) and the Korean, Vietnam, and Gulf Wars (hereafter "four wars") as well as operations in nine other locations included ever deployment to any war/operation, war/operation of longest deployment (i.e., the war or operation to which the veteran was deployed for the longest total time), total time of all deployments, and end of most recent deployment (Supplementary data, p. S3). We also had self-reported information on ever deployment to any other country; ever receiving imminent danger pay, hardship duty, or combat zone tax exclusion benefits for deployment to 17 foreign countries and/or five sea regions (plus fill-in options); and total time deployed to those countries/sea regions (Supplementary data, p. S3).

We had self-reported information on 39 specific military exposures, which we chose by adapting the questionnaires used in the Iowa Gulf War study (Doebbeling et al., 2002) and the Millennium Cohort Study (Ryan et al., 2007; Smith et al., 2009) for use in GENEVA (Beard, 2015; Schmidt et al., 2008). In addition, we added a few questions on exposures that were specific to one or more of the four wars (e.g., Agent Orange exposure during the Vietnam War). We queried 32 of 39 exposures only in reference to exposure during deployment to the four wars, which covered 16-231 cases and 30-338 controls depending on the war(s). For the seven non-war-specific exposures, information included ever exposure and, for some, a quantification of exposure (e.g., number of shots). For 31 of 32 war-specific exposures, we asked participants whether they had ever been exposed, days exposed (Not 
exposed, $\leq 5,6-30,>30$ ), and whether they felt ill after exposure (Not exposed, No, Yes). For the other war-specific exposure, total vaccinations, we had self-reported information on number of shots.

\subsection{Statistical analyses}

We identified risk factors for ALS from previous literature to consider as potential confounders (Supplementary data, p. S5). We used directed acyclic graphs (Greenland et al., 1999) to identify minimally sufficient adjustment sets (MSASs) among potential confounders (Supplementary data, Figure S.1 and p. S5). When military service factors were the explanatory variables of interest, the MSAS was age, sex, and race/ethnicity; when military deployments and exposures were of interest, the MSAS was age, sex, race/ethnicity, and branch of service. We also adjusted for VA health care use before diagnosis/interview date because it was a matching factor (Schmidt et al., 2008). We centered age at 60 yearsthe median age among controls-and modeled it with linear and quadratic terms. We used categorical variables to model the other covariates as follows: VA health care use (No, Yes), race/ethnicity (non-Hispanic White, other), and branch of service (Air Force, Army, Marines, Navy, other [e.g., Coast Guard, Reserves]).

We used unconditional logistic regression models to calculate odds ratios (ORs) and 95\% confidence intervals (CIs) for associations between military-related factors and ALS. We calculated three types of stabilized inverse probability weights (hereafter "weights") (Cole and Hernan, 2008; Hernan et al., 2004), a type of propensity score, to adjust for 1) matching factors and confounders in the MSASs, 2) potential bias resulting from missing data on ALSFRS-R score for $8 \%$ of Registry cases, and 3) potential selection bias from studying a case group that disproportionately included long-term survivors at GENEVA enrollment and a control group that may differ from U.S. military veterans at large (Schmidt et al., 2008; Schmidt et al., 2010) (Supplementary data, p. S6). We calculated confounding weights for each exposure separately, but used the same weights for missing ALSFRS-R score (cases only) and selection for every exposure. We evaluated appropriateness of the weights in our analyses using established criteria (Cole and Hernan, 2008) (Supplementary data, p. S11). We multiplied the three types of weights to obtain overall stabilized weights and applied these to unconditional logistic regression models containing the exposure of interest as the only explanatory variable in the same way sampling weights are applied when analyzing data from complex survey sampling designs (Cole and Hernan, 2008; Robins et al., 2000). We calculated $95 \%$ CIs using robust variance estimates because using weights for analysis induces within-subject correlation (Hernan et al., 2000). The weighted ORs and 95\% CIs thus generalize to the population of 1,785 Registry cases who had diagnoses of clinically definite, probable, possible, or suspected ALS and no missing data on covariates used to calculate the weights, and the population of 9,983 potential controls from the BIRLS database who had no missing data on covariates used to calculate the weights.

Nine of 32 war-specific exposures were distinct to a single war only. For these nine exposures (two Vietnam and seven Gulf War), our weights were inappropriate because they weighted GENEVA cases to represent all Registry cases and weighted GENEVA controls to represent all BIRLS potential controls regardless of age or era of service. To mitigate this 
problem for Vietnam War-specific exposures, we restricted analyses to Registry cases ( $\mathrm{n}=$ $302)$ and BIRLS potential controls $(n=3,793)$ who were ages $18-25$ years during that war. The small number of Gulf War veterans in our study precluded a similar approach for exposures distinct to that war.

To assess linear exposure-response trends for categorized versions of continuous variables, we used within-category medians as scores (Greenland, 2008) and scaled corresponding ORs to one unit or interquartile range (IQR) increases in the original continuous variables. We used category midpoints, and 50\% above the lower bound of the top category, as scores when assessing linear trends for days exposed to each of 31 exposures experienced during deployment to the four wars and scaled corresponding ORs to 20-day increases. We used ordinal scores to assess linear trends for feeling ill after exposure to each of the same 31 exposures.

We conducted several secondary analyses. We separately analyzed war-specific exposures for veterans deployed to the Vietnam War (cases: 64\% of those with war-specific data; controls: $80 \%$ ); too few veterans were deployed to other wars to conduct similar analyses for them. We conducted analyses within subsets chosen to reduce sample heterogeneity: cases who enrolled in GENEVA within two years of diagnosis (40\%); cases who had clinically definite or probable ALS (74\%); or participants who never visited or resided in western Pacific regions with high endemic ALS (Mitchell and Borasio, 2007) (cases: 84\%; controls: $80 \%$ ). To further explore confounding, we augmented models for the confounding weights by additionally including highest degree attained, rank, years of service, or war/operation of longest deployment one at a time. As alternative ways to control confounding by sex and race/ethnicity, we restricted analyses to men (cases: 98\%; controls: 93\%) or to non-Hispanic White men (cases: $90 \%$; controls: $82 \%$ ). To mitigate potential bias from exposure misclassification, we restricted analyses to non-proxy interviews (cases: 95\%; controls: $100 \%$ ). We recoded the reference date for controls to be 30 months (i.e., the median time between diagnosis and interview for cases) earlier because, since cases and controls were asked to use their diagnosis and interview dates, respectively, as the reference date (Schmidt et al., 2008), controls may have had more time than cases to be exposed. For analyses involving the 39 military exposures, we calculated Spearman correlation coefficients to identify correlated exposures and then mutually-adjusted exposures whose correlation coefficients exceeded 0.2 in absolute value. Finally, we used standard regression methods to adjust for potential confounding, but without weighting for potential bias from selection or missing baseline ALSFRS-R score. We performed all analyses with SAS version 9.3 (SAS Institute Inc., Cary, NC, 2011).

\section{Results}

Cases and controls were closely matched on age and use of VA health care (Table 1). After adjustment for these matching factors, the odds of ALS were lower among women, veterans of a race/ethnicity other than non-Hispanic White, and those with more education compared to men, non-Hispanic Whites, or those with less education, respectively. Clinical characteristics of cases are shown in Table 2. 
In weighted analyses, the odds of ALS did not differ among veterans of the Air Force, Army, Marines, and Navy, but ALS was less common among veterans of other branches (e.g., Coast Guard, Reserves) and among veterans who had been officers compared to non-officers (Table 3). We observed inverse trends between ALS and number of service branches as well as years of service and end of most recent service.

ALS was more common among veterans whose longest deployment was to WWII or the Korean War, but less common among veterans whose longest deployment was to operations other than the four wars, compared to those not deployed (Table 4). We found an inverse trend between ALS and end of most recent deployment. ALS was inversely associated with ever receiving danger pay and had an inverse trend with cumulative time of receipt of danger pay.

Weighted results for ever experiencing specific exposures during service or deployment to the four wars are presented in Table 5, whereas weighted results from analyses of exposureresponse trends and feeling ill after exposure are in Supplementary data (Tables S.1-S.2. Among exposures experienced any time during service, anthrax vaccination, herbicides used for military purposes, nasopharyngeal radium, and pyridostigmine bromide all had ORs for ALS of at least 1.50, although none had exposure-response trends. Among exposures experienced during deployment to the four wars, ever exposure to exhaust from heaters or generators, high-intensity radar waves, explosions within one mile, herbicides in the field, mixing and application of burning agents, burning agents in the field, and Agent Orange in the field all had ORs for ALS of at least 1.50 and had positive exposure-response trends. Moreover, all seven of these exposures had higher odds of ALS among those who felt ill after exposure compared to those not exposed, although some of the exposures (highintensity radar waves, herbicides in the field, and mixing and application of burning agents) had fewer than five cases or controls who felt ill after exposure. In addition, total number of preventive vaccinations received, heat illness, and microwave radiation had positive exposure-response trends. Odds of ALS were higher among those who felt ill after exposure to pesticides on clothing or bedding and riot control substances in the field compared to those not exposed; however, fewer than five cases felt ill after exposure to riot control substances in the field.

Results from sub-analyses restricted to Vietnam War-deployed veterans were generally similar (Supplementary data, Tables S.3-S.6), although the OR for exposure to pesticides on clothing or bedding was greater than $1.50(\mathrm{OR}=1.83$; $95 \%$ CI: $0.99,3.40)$. Results were also similar in analyses of restricted subsets designed to reduce sample heterogeneity, to control confounding by sex and race/ethnicity, or to mitigate potential bias from exposure misclassification (not shown). Augmenting models for the confounding weights by additionally including highest degree attained or rank one at a time gave similar results. Many of the inverse associations we observed between ALS and military service and deployment factors (e.g., rank, ever receiving danger pay, cumulative time of receipt of danger pay) attenuated when we additionally included years of service in the models for the confounding weights, but the most notable change was a positive trend between ALS and total time of all deployments ( $\leq 1$ year: $\mathrm{OR}=0.96 ; 95 \% \mathrm{CI}: 0.69,1.35 ;>1-2$ years: $\mathrm{OR}=$ 0.79 ; $95 \%$ CI: $0.47,1.35$; $>2-3$ years: $\mathrm{OR}=2.14 ; 95 \% \mathrm{CI}: 0.90,5.12 ;>3-5$ years: $\mathrm{OR}=$ 
2.99; 95\% CI: 0.80, 11.09; > 5 years: $\mathrm{OR}=2.93 ; 95 \%$ CI: $0.65,13.30$; trend for a one-year increase: $\mathrm{OR}=1.27 ; 95 \% \mathrm{CI}: 1.06,1.52$ ). Additionally including war/operation of longest deployment in models for the confounding weights increased ORs above 1.50 for exposure to personal pesticides $(\mathrm{OR}=1.61 ; 95 \% \mathrm{CI}$ : $0.91,2.85)$ and contaminated food $(\mathrm{OR}=2.05$; 95\% CI: 0.90, 4.69). Recoding the reference date for controls to be 30 months (i.e., the median time between diagnosis and interview for cases) earlier gave similar results (not shown). Most correlation coefficients for associations between exposures were less than 0.2 in absolute value; mutual adjustment of more strongly correlated exposures left results unchanged (not shown). Finally, results using standard regression methods to adjust for potential confounding, but without weighting for potential bias from selection or missing baseline ALSFRS-R score, were generally similar qualitatively with a few exceptions (Supplementary data, Tables S.1-S.9, “Adjusted” columns).

\section{Discussion}

In contrast to prior etiological studies of ALS among military veterans which relied upon death certificate diagnoses, GENEVA obtained medical record-confirmed diagnoses of ALS. In addition, GENEVA has a relatively large sample size compared to prior studies, although the number of exposed cases available for analyses of some exposures in the current analysis, particularly those specific to the Gulf War, was small. This study collected extensive information on military service and deployment factors as well as on 39 specific exposures. Our results were similar in sub-analyses that created a more homogeneous sample or that attempted to reduce potential biases. Finally, we used inverse probability weighting to explore and control potential bias from confounding, missing baseline ALSFRS-R score (cases only), and selection arising from a case group that disproportionately included long-term survivors and a control group that may differ from U.S. military veterans at large.

Using these data, we found no difference in the odds of ALS among veterans of the Air Force, Army, Marines, and Navy, but higher odds among veterans whose longest deployment was WWII or the Korean War and a positive trend with total time of all deployments. ALS was more common among veterans who were exposed to specific exposures experienced during service or deployment to the four wars, including pesticide-, chemical-, and radiation-related exposures. Results were similar in several secondary analyses, for example after restricting to cases enrolled within two years of diagnosis, to cases who had definite or probable ALS, or to participants who did not require a proxy interview.

Several studies have evaluated associations between characteristics of military service and ALS. ALS incidence or mortality was positively associated with deployment to the Gulf War in five of seven studies (Barth et al., 2009; Coffman et al., 2005; Haley, 2003; Horner et al., 2008; Horner et al., 2003; Kang and Bullman, 2001; Smith et al., 2000) and not associated with service in the Korean War in another (Kurtzke and Beebe, 1980). Service during the time of WWII was positively associated with ALS mortality in one study (Weisskopf et al., 2015), but time period of service was not associated with ALS hospitalization or mortality in three others (Bergman et al., 2015; Fang et al., 2009; Seals et al., 2015; Weisskopf et al., 
2005). Four studies found no association between service branch and ALS incidence or mortality (Binazzi et al., 2009; Fang et al., 2009; Kurtzke and Beebe, 1980; Weisskopf et al., 2005), but a spatial analysis of Gulf War veterans observed significantly lower ALS incidence for members of the Marine Corps compared to the Army (Miranda et al., 2008). Years of service was not associated with ALS incidence or mortality in three studies (Bergman et al., 2015; Fang et al., 2009; Weisskopf et al., 2005), but another study found elevated rates of ALS hospitalization with increasing years of service (Seals et al., 2015). Highest rank attained was not associated with ALS deaths in another study (Kurtzke and Beebe, 1980). To our knowledge, no previous study has evaluated associations between total time of all deployments and ALS. In our study, the odds of ALS were higher among veterans whose longest deployment was to WWII or the Korean War, had a positive trend with total time of all deployments, did not vary across the four major branches, had an inverse trend with years of service and end of most recent service, and were lower among officers, although this last result attenuated in secondary analyses. Reasons we did not find a positive association between ALS and deployment to the Gulf War are unknown, but could be related to differences between previous studies and our study in the exposure metric (ever vs. longest deployment), choice of comparison group (Gulf War era veterans not deployed or deployed elsewhere vs. veterans of all eras not deployed to any war/operation), time period of case identification (Horner et al. (Horner et al., 2003) identified cases for the period 1990-2000, whereas we identified cases from 2005 to 2010), or sample size (Horner et al. (Horner et al., 2003) identified 40 deployed cases, whereas we identified 11).

There are at least three possible explanations for the inverse associations we observed between ALS and military service and deployment factors. First, our control group may have included many longer-serving veterans. For example, we observed significant inverse trends between ALS and number of service branches and years of service. The odds of ALS were also lower among veterans who had been officers or who had education beyond high school. In addition, the odds were lower among veterans whose longest service was in branches other than the Air Force, Army, Marines, or Navy; this category included 36 cases and 168 controls whose longest service branch was National Guard or Reserves. We attempted to remove this apparent selection bias through the use of weights, but residual selection bias is possible. Second, these inverse associations may have been confounded by years of service, which seems likely because many of these associations attenuated when we additionally included years of service in models for the confounding weights. Finally, the healthy worker survivor effect, which occurs when those who stay in the workforce (i.e., military) over time are healthier than those who die or drop out (Arrighi and Hertz-Picciotto, 1994), may have contributed to the inverse associations we observed. We are unaware of any statistical methods currently available to correct bias from the healthy worker survivor effect in casecontrol studies, particularly ones that sampled cases and controls from those available at the end of follow-up, as ours did.

We found positive associations between ALS and exposures experienced during service or deployment to the four wars: pesticides and related compounds (herbicides in general, Agent Orange in particular, pyridostigmine bromide, personal pesticides); certain chemicals (exhaust from heaters or generators, burning agents), radiation (nasopharyngeal radium, high-intensity radar), and other exposures (anthrax vaccination, contaminated food, 
explosions within one mile). Several of these findings are consistent with results of general population studies and meta-analyses of associations between ALS and exposure to pesticides (Kamel et al., 2012; Malek et al., 2012), chemicals or solvents (McGuire et al., 1997; Pamphlett, 2012), and magnetic fields (i.e., non-ionizing radiation) (Vergara et al., 2013). These findings also agree with a study of male U.S. Army Chemical Corps veterans who were responsible for mixing and applying herbicides (including Agent Orange), riot control substances, and burning agents during the Vietnam War. That study found these veterans to have a non-significantly elevated rate of mortality from nervous system diseases relative to the entire U.S. male population (Thomas and Kang, 1990). A study of Vietnam veterans from Korea found a positive association between Agent Orange and self-reported ALS when based on a self-reported perceived Agent Orange exposure index (Yi et al., 2013), but no association when employing two separate geographic information system (GIS) models to assess exposure (Yi et al., 2013). Another study of the same population reported no association between GIS-based exposure to Agent Orange and ALS identified via health insurance claims data (Yi et al., 2014). In our study, the publicity surrounding Agent Orange exposure may have led to its being over-reported-more so by cases than controls - particularly for those who reported exposure in the field. Therefore, we explored the plausibility of veterans' self-reported Agent Orange exposures and found that $90 \%$ (cases: 88\%; controls: 92\%) and 94\% (cases: 88\%; controls: 99\%) of veterans who reported mixing and applying or exposure in the field, respectively, reported being in Vietnam during the time Agent Orange was used (i.e., 1965-1970) (Institute of Medicine, 1994). In addition, excluding individuals with implausible values for these exposures gave slightly attenuated, but qualitatively similar, results (not shown). These results should be interpreted cautiously, however, because we could not directly validate self-reported Agent Orange exposure.

Our finding of a positive association between ALS and explosions within one mile is difficult to interpret. This exposure may have been a marker of lower socioeconomic status or rank because veterans who were less educated or non-officers may have been more likely to be directly involved in combat and, therefore, exposed to explosions than veterans who were more educated or officers. Our data did not support this explanation, however, because results were similar when we adjusted for highest degree attained or rank (not shown). Explosions within one mile may have been correlated with other combat-related exposures, but results were similar when we mutually-adjusted correlated exposures (not shown). Furthermore, the largest partial Spearman correlation coefficient between explosions within one mile and the other war-specific exposures in our study was only 0.27 (combat-related injury). Finally, explosions within one mile could have caused stress or trauma, which may be a risk factor for ALS (Pupillo et al., 2012). Our data did not support this explanation, however, because veterans who reported any other exposure or experience not asked about which they considered harmful or extremely stressful did not have increased odds of ALS $(\mathrm{OR}=0.81 ; 95 \% \mathrm{CI}: 0.48,1.38)$, although this exposure had substantial missing data. Thus, explanations for a positive association between ALS and explosions within one mile are unknown.

Reporting errors may explain, at least in part, the positive associations we observed between ALS and anthrax vaccination or pyridostigmine bromide if cases were more likely than controls to report military service during times these exposures were not encountered. In 
fact, some veterans who reported these exposures served in the military in the 1950s and 1960s even though anthrax vaccination was not available until 1998 (Smith et al., 2007a) and pyridostigmine bromide was available only during the Gulf War and for combat since 2003 (U.S. Food and Drug Administration, 2003). Excluding individuals with implausible values for these exposures removed the positive associations (anthrax vaccination: OR = 0.60; $95 \%$ CI: $0.22,1.64$; pyridostigmine bromide: $\mathrm{OR}=0.49 ; 95 \%$ CI: $0.14,1.73$ ).

Our findings of no association between smallpox vaccination and ALS, but a borderline significant trend for total number of preventive vaccinations, suggests ALS may be associated with vaccinations only at high levels of exposure or only for other vaccines. Another study, however, reported no association between ALS deaths and immunizations during service (Kurtzke and Beebe, 1980). A study found no association between ALS mortality and exposure to smoke from oil well fires during deployment to the Gulf War (Barth et al., 2009), which agrees with our result.

Associations we observed between ALS and specific exposures experienced during deployment to the four wars may have been confounded by other exposures experienced during military service or civilian life. We did not adjust analyses for non-military exposures, but mutual adjustment for correlated military exposures gave similar results, mitigating this concern.

We examined the appropriateness of the weights used in our analysis. Means of truncated overall stabilized weights were typically near one and extreme weights were rare (not shown). Time-related variables, such as end of most recent service or deployment, were usually the exceptions. Cross-tabulations of age and the affected variables showed empty cells, particularly in the extreme combinations of age and the variables (not shown), which compromise weighted analyses. These empty cells are likely structural rather than random (Cole and Hernan, 2008), because, for example, Gulf War veterans were very unlikely to have been > 79 years-old when GENEVA was conducted. Collapsing categories of both age and the affected variables fixed the problem and gave similar ORs and 95\% CIs compared to the expanded versions (not shown).

We were only able to weight GENEVA cases to represent Registry cases, so our results do not generalize to veteran cases who died before Registry enrollment began in 2003 (Pastula et al., 2009) or who did not join the Registry for other reasons. Furthermore, the median time from Registry enrollment to GENEVA enrollment was nine ( IQR $=11)$ months, a short period compared to elapsed time since diagnosis for long-surviving cases. Additionally, the BIRLS sample of potential controls is likely missing a subset of veterans whose release of active duty date was before 1973 (Schmidt et al., 2008). The age distribution of the BIRLS sample is also different from that of the general veteran population because it was agestratified. However, results were similar when we included a stabilized selection weight to weight the BIRLS sample to the age distribution of all U.S. military veterans in 2005 using data from the American Community Survey (Bureau of the Census, 2012). Nevertheless, residual selection bias could have affected our results, particularly because we did not have information on education or military rank- two factors inversely associated with ALS in our study—for the BIRLS sample. 
Using cases from the Registry to study ALS has inherent limitations. Despite a national recruiting effort (Allen et al., 2008), under-ascertainment of cases in the Registry seems likely, especially considering the likely under-ascertainment of cases among non-deployed veterans in the VA's previous Gulf War ALS study (Coffman et al., 2005; Horner et al., 2003). In addition, Registry cases are a mix of incident and long-surviving, prevalent cases (Schmidt et al., 2008; Schmidt et al., 2010). Confidence in our results is increased, however, because results changed little after we restricted to cases enrolled in GENEVA within two years of diagnosis.

Lack of suitable biomarkers and sufficiently detailed military databases for most exposures evaluated here necessitated the use of self-report. The validity and reliability of a number of self-reported military-related factors have been evaluated by several studies, usually in comparison to data from the U.S. Department of Defense's Defense Manpower Data Center, and been characterized as ranging from "moderate" (e.g., $\kappa=0.41-0.60)$ to "almost perfect" (e.g., $\kappa>0.80$ ) (Bramsen et al., 2001; Horner et al., 2003; Janes et al., 1991; LeardMann et al., 2007; Mahan, 2004; Roemer et al., 1998; Smith et al., 2007a; Smith et al., 2007b; Smith et al., 2007c; Southwick et al., 1997). Military-related factors evaluated in validity studies included deployment status and frequency, number, and start dates of deployment(s) (Horner et al., 2003; Smith et al., 2007b); occupational titles (Smith et al., 2007c); and anthrax (LeardMann et al., 2007; Smith et al., 2007a) or smallpox vaccination (Mahan, 2004). Reliability studies evaluated combat-related experiences, exposures, or traumatic events (Bramsen et al., 2001; Janes et al., 1991; Roemer et al., 1998; Southwick et al., 1997) and exposure indices created by summing or averaging participants' responses for individual items (Bramsen et al., 2001; Janes et al., 1991; Roemer et al., 1998; Southwick et al., 1997). None of these studies, however, were able to assess the validity or reliability of self-reported military-related factors extending back to WWII (the longest time between exposure and exposure assessment in these studies was about 10 years (Horner et al., 2003)) or whether the quality of self-report varied by war or time period.

In general, we expect military service factors, such as branch of service or rank, to be reported more validly and reliably than military deployment factors, such as war/operation of deployment or dates of deployment, which would be reported more validly and reliably than specific military exposures because this pattern has been observed in other occupational epidemiology studies (i.e., job title is reported more validly and reliably than dates of employment or job tasks, which are reported more validly and reliably than specific occupational exposures) (Teschke et al., 2002). Importantly, there seems to be little evidence that cases of various diseases recall past occupational factors and exposures differently than controls (Teschke et al., 2002). Furthermore, efforts were made to improve recall in GENEVA by: asking participants about exposures that can be sensed (e.g., explosions within one mile), using general terms (e.g., flea collar rather than specific pesticides), querying a list of specific exposures, and providing benchmarks against which respondents could compare their levels of exposure (e.g., feeling ill after exposure) (Schmidt et al., 2008). Finally, restricting analyses to non-proxy interviews did not substantively change results. 


\section{Conclusions}

In this large study that included detailed information on several military-related factors and employed sophisticated analytic approaches to minimize bias, the odds of ALS did not differ among veterans of the Air Force, Army, Marines, and Navy and were higher among veterans whose longest deployment was to WWII or the Korean War. There was also a positive trend between ALS and total time of all deployments. ALS was more common among veterans who were exposed to specific exposures experienced during service or deployment to the four wars-including pesticide-, chemical-, and radiation-related exposures-which are similar to those associated with ALS in other studies of military veterans or the general population. These results require replication and further study, especially because some of them may have been confounded by other exposures experienced during military service or civilian life. Nevertheless, these results are potentially important given the large number of U.S. military veterans and they provide clues to the potential causal factor(s) underlying the apparent increase of ALS in veteran populations.

\section{Supplementary Material}

Refer to Web version on PubMed Central for supplementary material.

\section{Acknowledgments}

We thank the participants in GENEVA without whom the study would have been impossible. We thank Lydia Kwee, Marcus Johnson, Cynthia Coffman, Jennifer Lindquist, Eugene Oddone, and Dawn Provenzale for helping us obtain data from GENEVA and the National Registry of Veterans with ALS. The views expressed in this article are those of the authors and do not necessarily represent the views of the Department of Veterans Affairs or the United States Government.

Funding sources

This work was supported by the Intramural Research Program of the NIH, National Institute of Environmental Health Sciences (NIEHS; Z01 ES049005), grants from the NIEHS (R01 ES13244) and the ALS Association (ALSA 1230), and training grants from the NIEHS (T32ES007018) and the CDC, National Institute for Occupational Safety and Health (T42OH00867302). The National Registry of Veterans with ALS was supported by the U.S. Department of Veterans Affairs (CSP \#500A).

\section{Abbreviations}

ALS

ALSFRS-R

BIRLS

CARC

CI

DU

four wars

GENEVA amyotrophic lateral sclerosis

ALS Functional Rating Scale-Revised

Beneficiary Identification and Records Locator System

Chemical Agent Resistant Compound

confidence interval

depleted uranium

World War II and the Korean, Vietnam, and 1990-1991 Persian Gulf War

Genes and Environmental Exposures in Veterans with Amyotrophic Lateral Sclerosis study 


$\begin{array}{ll}\text { GIS } & \text { geographic information system } \\ \text { Gulf War } & 1990-1991 \text { Persian Gulf War } \\ \text { IQR } & \text { interquartile range } \\ \text { IP } & \text { inverse probability } \\ \text { MSAS } & \text { minimally sufficient adjustment set } \\ \text { NP } & \text { nasopharyngeal } \\ \text { NIEHS } & \text { National Institute of Environmental Health Sciences } \\ \text { OR } & \text { odds ratio } \\ \text { PLS } & \text { primary lateral sclerosis } \\ \text { Registry } & \text { U.S. National Registry of Veterans with ALS } \\ \text { VA } & \text { U.S. Department of Veterans Affairs } \\ \text { weight } & \text { inverse probability weight } \\ \text { WWII } & \text { World War II }\end{array}$

\section{References}

Allen KD, Kasarskis EJ, Bedlack RS, Rozear MP, Morgenlander JC, Sabet A, et al. The National Registry of Veterans with amyotrophic lateral sclerosis. Neuroepidemiology. 2008; 30:180-190. [PubMed: 18421218]

Arrighi HM, Hertz-Picciotto I. The evolving concept of the healthy worker survivor effect. Epidemiology. 1994; 5:189-196. [PubMed: 8172994]

Barth SK, Kang HK, Bullman TA, Wallin MT. Neurological mortality among U.S. veterans of the Persian Gulf War: 13-year follow-up. Am J Ind Med. 2009; 52:663-670. [PubMed: 19585544]

Beard, JD. Epidemiology. Chapel Hill, NC: University of North Carolina at Chapel Hill; 2015. Military Service, Deployments, and Exposures in Relation to Amyotrophic Lateral Sclerosis Etiology and Survival.

Beard JD, Kamel F. Military service, deployments, and exposures in relation to amyotrophic lateral sclerosis etiology and survival. Epidemiol Rev. 2015; 37:55-70. [PubMed: 25365170]

Bergman BP, Mackay DF, Pell JP. Motor neurone disease and military service: evidence from the Scottish Veterans Health Study. Occup Environ Med. 2015; 72:877-879. [PubMed: 26468494]

Binazzi A, Belli S, Uccelli R, Desiato MT, Talamanca IF, Antonini G, et al. An exploratory casecontrol study on spinal and bulbar forms of amyotrophic lateral sclerosis in the province of Rome. Amyotroph Lateral Scler. 2009; 10:361-369. [PubMed: 19922125]

Bramsen I, Dirkzwager AJ, van Esch SC, van der Ploeg HM. Consistency of self-reports of traumatic events in a population of Dutch peacekeepers: reason for optimism? J Trauma Stress. 2001; 14:733740. [PubMed: 11776420]

Brooks BR, Miller RG, Swash M, Munsat TL. World Federation of Neurology Research Group on Motor Neuron, D. El Escorial revisited: revised criteria for the diagnosis of amyotrophic lateral sclerosis. Amyotroph Lateral Scler Other Motor Neuron Disord. 2000; 1:293-299. [PubMed: 11464847]

Bureau of the Census, US Department of Commerce. American Community Survey 1-Year Estimates. Washington, DC: Bureau of the Census; 2012.

Cedarbaum JM, Stambler N, Malta E, Fuller C, Hilt D, Thurmond B, et al. The ALSFRS-R: a revised ALS functional rating scale that incorporates assessments of respiratory function. BDNF ALS Study Group (Phase III). J Neurol Sci. 1999; 169:13-21. [PubMed: 10540002] 
Coffman CJ, Horner RD, Grambow SC, Lindquist J, Project VACSP. Estimating the occurrence of amyotrophic lateral sclerosis among Gulf War (1990-1991) veterans using capture-recapture methods. Neuroepidemiology. 2005; 24:141-150. [PubMed: 15650320]

Cole SR, Hernan MA. Constructing inverse probability weights for marginal structural models. Am J Epidemiol. 2008; 168:656-664. [PubMed: 18682488]

Doebbeling BN, Jones MF, Hall DB, Clarke WR, Woolson RF, Torner JC, et al. Methodologic issues in a population-based health survey of Gulf War veterans. J Clin Epidemiol. 2002; 55:477-487. [PubMed: 12007551]

Fang F, Quinlan P, Ye W, Barber MK, Umbach DM, Sandler DP, et al. Workplace exposures and the risk of amyotrophic lateral sclerosis. Environ Health Perspect. 2009; 117:1387-1392. [PubMed: 19750102]

Greenland, S. Introduction to regression models. In: Rothman, KJ.; Greenland, S.; Lash, TL., editors. Modern Epidemiology. Philadelphia, PA: Lippincott, Williams, \& Wilkins; 2008.

Greenland S, Pearl J, Robins JM. Causal diagrams for epidemiologic research. Epidemiology. 1999; 10:37-48. [PubMed: 9888278]

Haley RW. Excess incidence of ALS in young Gulf War veterans. Neurology. 2003; 61:750-756. [PubMed: 14504316]

Hernan MA, Brumback B, Robins JM. Marginal structural models to estimate the causal effect of zidovudine on the survival of HIV-positive men. Epidemiology. 2000; 11:561-570. [PubMed: 10955409]

Hernan MA, Hernandez-Diaz S, Robins JM. A structural approach to selection bias. Epidemiology. 2004; 15:615-625. [PubMed: 15308962]

Horner RD, Grambow SC, Coffman CJ, Lindquist JH, Oddone EZ, Allen KD, et al. Amyotrophic lateral sclerosis among 1991 Gulf War veterans: evidence for a time-limited outbreak. Neuroepidemiology. 2008; 31:28-32. [PubMed: 18535397]

Horner RD, Kamins KG, Feussner JR, Grambow SC, Hoff-Lindquist J, Harati Y, et al. Occurrence of amyotrophic lateral sclerosis among Gulf War veterans. Neurology. 2003; 61:742-749. [PubMed: 14504315]

Institute of Medicine. Institute of Medicine. Washington, DC: National Academies Press; 1994. Veterans and Agent Orange: Health Effects of Herbicides Used in Vietnam.

Janes GR, Goldberg J, Eisen SA, True WR. Reliability and validity of a combat exposure index for Vietnam era veterans. J Clin Psychol. 1991; 47:80-86. [PubMed: 2026782]

Kamel F, Umbach DM, Bedlack RS, Richards M, Watson M, Alavanja MC, et al. Pesticide exposure and amyotrophic lateral sclerosis. Neurotoxicology. 2012; 33:457-462. [PubMed: 22521219]

Kang HK, Bullman TA. Mortality among US veterans of the Persian Gulf War: 7-year follow-up. Am J Epidemiol. 2001; 154:399-405. [PubMed: 11532780]

Kasarskis EJ, Dominic K, Oddone EZ. The National Registry of Veterans with Amyotrophic Lateral Sclerosis: Department of Veterans Affairs Cooperative Studies Program (CSP) \#500a. Amyotroph Lateral Scler Other Motor Neuron Disord. 2004; 5:129-132. [PubMed: 15512895]

Kurtzke JF, Beebe GW. Epidemiology of amyotrophic lateral sclerosis: 1. A case-control comparison based on ALS deaths. Neurology. 1980; 30:453-462. [PubMed: 7189251]

LeardMann CA, Smith B, Smith TC, Wells TS, Ryan MA. Millennium Cohort Study, T. Smallpox vaccination: comparison of self-reported and electronic vaccine records in the millennium cohort study. Hum Vaccin. 2007; 3:245-251. [PubMed: 17700077]

Mahan C. Anthrax vaccination and self-reported symptoms, functional status, and medical conditions in the National Health Survey of Gulf War Era Veterans and Their Families. Ann Epidemiol. 2004; 14:81-88. [PubMed: 15018879]

Malek AM, Barchowsky A, Bowser R, Youk A, Talbott EO. Pesticide exposure as a risk factor for amyotrophic lateral sclerosis: a meta-analysis of epidemiological studies: pesticide exposure as a risk factor for ALS. Environ Res. 2012; 117:112-119. [PubMed: 22819005]

McGuire V, Longstreth WT Jr, Nelson LM, Koepsell TD, Checkoway H, Morgan MS, et al. Occupational exposures and amyotrophic lateral sclerosis. A population-based case-control study. Am J Epidemiol. 1997; 145:1076-1088. [PubMed: 9199537] 
Miranda ML, Overstreet Galeano MA, Tassone E, Allen KD, Horner RD. Spatial analysis of the etiology of amyotrophic lateral sclerosis among 1991 Gulf War veterans. Neurotoxicology. 2008; 29:964-970. [PubMed: 18573277]

Mitchell JD, Borasio GD. Amyotrophic lateral sclerosis. Lancet. 2007; 369:2031-2041. [PubMed: 17574095]

Pamphlett R. Exposure to environmental toxins and the risk of sporadic motor neuron disease: an expanded Australian case-control study. Eur J Neurol. 2012; 19:1343-1348. [PubMed: 22642256]

Pastula DM, Coffman CJ, Allen KD, Oddone EZ, Kasarskis EJ, Lindquist JH, et al. Factors associated with survival in the National Registry of Veterans with ALS. Amyotroph Lateral Scler. 2009; 10:332-338. [PubMed: 19922120]

Pupillo E, Messina P, Logroscino G, Zoccolella S, Chio A, Calvo A, et al. Trauma and amyotrophic lateral sclerosis: a case-control study from a population-based registry. Eur J Neurol. 2012; 19:1509-1517. [PubMed: 22537412]

Robins JM, Hernan MA, Brumback B. Marginal structural models and causal inference in epidemiology. Epidemiology. 2000; 11:550-560. [PubMed: 10955408]

Roemer L, Litz BT, Orsillo SM, Ehlich PJ, Friedman MJ. Increases in retrospective accounts of warzone exposure over time: the role of PTSD symptom severity. J Trauma Stress. 1998; 11:597-605. [PubMed: 9690197]

Ryan MA, Smith TC, Smith B, Amoroso P, Boyko EJ, Gray GC, et al. Millennium Cohort: enrollment begins a 21-year contribution to understanding the impact of military service. J Clin Epidemiol. 2007; 60:181-191. [PubMed: 17208125]

Schmidt S, Allen KD, Loiacono VT, Norman B, Stanwyck CL, Nord KM, et al. Genes and Environmental Exposures in Veterans with Amyotrophic Lateral Sclerosis: the GENEVA study. Rationale, study design and demographic characteristics. Neuroepidemiology. 2008; 30:191-204. [PubMed: 18421219]

Schmidt S, Kwee LC, Allen KD, Oddone EZ. Association of ALS with head injury, cigarette smoking and APOE genotypes. J Neurol Sci. 2010; 291:22-29. [PubMed: 20129626]

Seals RM, Kioumourtzoglou MA, Gredal O, Hansen J, Weisskopf MG. ALS and the Military: A Population-Based Study in the Danish Registries. Epidemiology. 2015 ahead of print.

Smith B, Leard CA, Smith TC, Reed RJ, Ryan MA. Millennium Cohort Study, T. Anthrax vaccination in the Millennium Cohort: validation and measures of health. Am J Prev Med. 2007a; 32:347-353. [PubMed: 17383567]

Smith B, Wingard DL, Ryan MA, Macera CA, Patterson TL, Slymen DJUS. military deployment during 2001-2006: comparison of subjective and objective data sources in a large prospective health study. Ann Epidemiol. 2007b; 17:976-982. [PubMed: 17923418]

Smith TC, Gray GC, Knoke JD. Is systemic lupus erythematosus, amyotrophic lateral sclerosis, or fibromyalgia associated with Persian Gulf War service? An examination of Department of Defense hospitalization data. Am J Epidemiol. 2000; 151:1053-1059. [PubMed: 10873128]

Smith TC, Jacobson IG, Smith B, Hooper TI, Ryan MA. Millennium Cohort Study, T. The occupational role of women in military service: validation of occupation and prevalence of exposures in the Millennium Cohort Study. Int J Environ Health Res. 2007c; 17:271-284. [PubMed: 17613091]

Smith TC. Millennium Cohort Study, T. The US Department of Defense Millennium Cohort Study: career span and beyond longitudinal follow-up. J Occup Environ Med. 2009; 51:1193-1201. [PubMed: 19786902]

Southwick SM, Morgan CA, Nicolaou AL 3rd, Charney DS. Consistency of memory for combatrelated traumatic events in veterans of Operation Desert Storm. Am J Psychiatry. 1997; 154:173177. [PubMed: 9016264]

Sutedja NA, Veldink JH, Fischer K, Kromhout H, Wokke JH, Huisman MH, et al. Lifetime occupation, education, smoking, and risk of ALS. Neurology. 2007; 69:1508-1514. [PubMed: 17923612]

Teschke K, Olshan AF, Daniels JL, De Roos AJ, Parks CG, Schulz M, et al. Occupational exposure assessment in case-control studies: opportunities for improvement. Occup Environ Med. 2002; 59:575-593. discussion 94. [PubMed: 12205230] 
Thomas TL, Kang HK. Mortality and morbidity among Army Chemical Corps Vietnam veterans: a preliminary report. Am J Ind Med. 1990; 18:665-673. [PubMed: 2264565]

U.S. Food and Drug Administration. FDA Approves Pyridostigmine Bromide as Pretreatment Against Nerve Gas. U.S. Food and Drug Administration. 2003

Vergara X, Kheifets L, Greenland S, Oksuzyan S, Cho YS, Mezei G. Occupational exposure to extremely low-frequency magnetic fields and neurodegenerative disease: a meta-analysis. J Occup Environ Med. 2013; 55:135-146. [PubMed: 23389409]

Weisskopf MG, Cudkowicz ME, Johnson N. Military service and amyotrophic lateral sclerosis in a population-based cohort. Epidemiology. 2015; 26:831-838. [PubMed: 26414854]

Weisskopf MG, O’Reilly EJ, McCullough ML, Calle EE, Thun MJ, Cudkowicz M, et al. Prospective study of military service and mortality from ALS. Neurology. 2005; 64:32-37. [PubMed: 15642900]

World Health Organization. International Statistical Classification of Diseases and Related Health Problems. Geneva, Switzerland: World Health Organization; 1977.

Yi SW, Hong JS, Ohrr H, Yi JJ. Agent Orange exposure and disease prevalence in Korean Vietnam veterans: the Korean veterans health study. Environ Res. 2014; 133:56-65. [PubMed: 24906069]

Yi SW, Ohrr H, Hong JS, Yi JJ. Agent Orange exposure and prevalence of self-reported diseases in Korean Vietnam veterans. J Prev Med Public Health. 2013; 46:213-225. [PubMed: 24137524] 


\section{Highlights}

- We evaluate military factors in relation to amyotrophic lateral sclerosis (ALS).

- We study aspects of service, deployments, and 39 military exposures among veterans.

- Veterans of the Air Force, Army, Marines, and Navy had similar odds of ALS.

- Veterans deployed to World War II or the Korean War had elevated odds of ALS.

- Nine pesticide, chemical, radiation, and other exposures increased odds of ALS. 


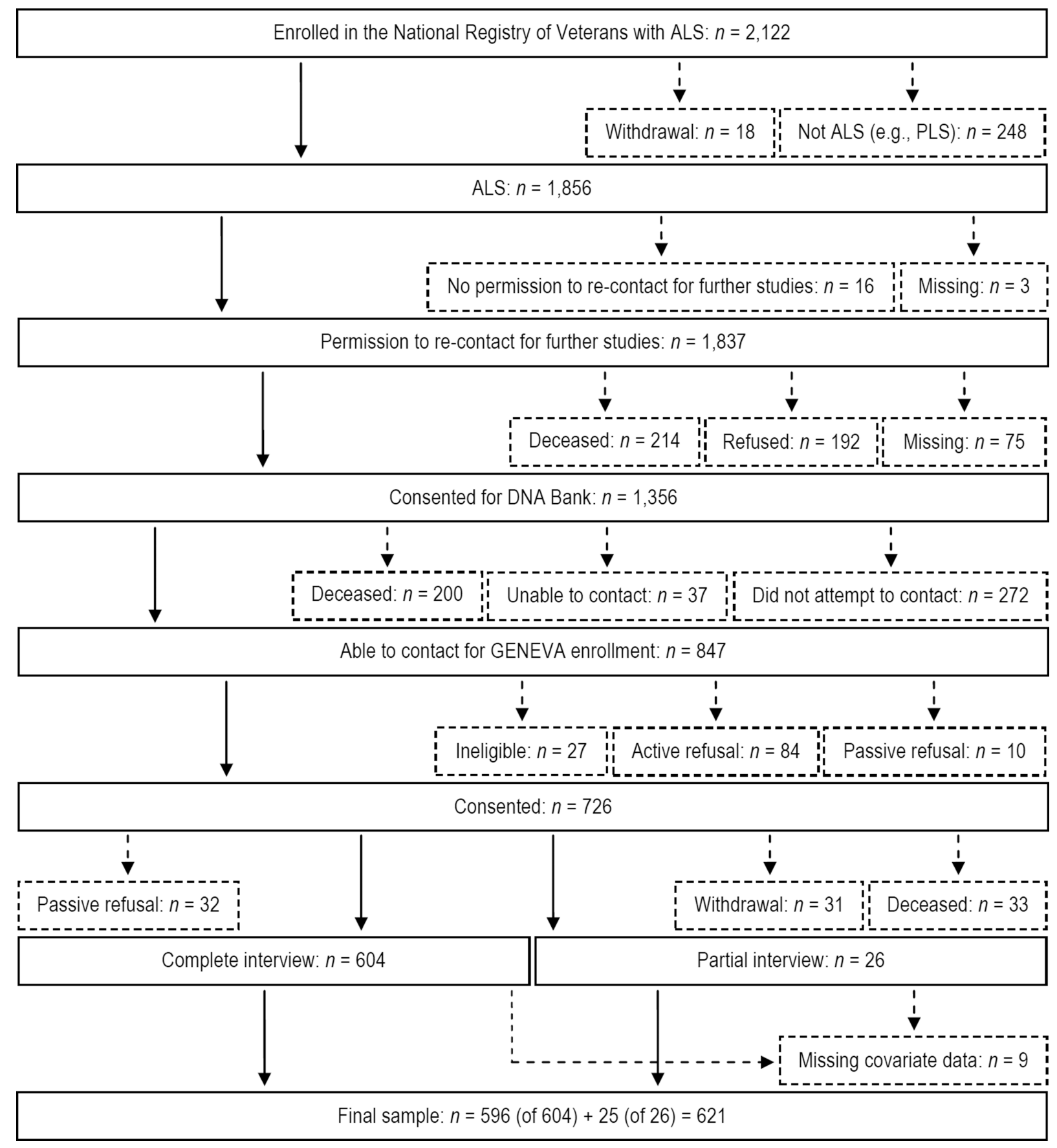

Figure 1.

Flow diagram depicting the ascertainment of GENEVA cases. Solid boxes or lines represent cases who advanced past each step shown. Small-dashed boxes or lines represent cases who were excluded after each step shown, but who were incorporated into the analysis via inverse probability weights (see Section 2.3 and Supplementary data, p. S6, for more details).

Reasons cases were ineligible for GENEVA included dementia $(n=9)$, diagnosis change ( $n$ $=2)$, withdrawal from the Registry DNA bank $(n=3)$, or interview infeasibility $(n=11)$.

Abbreviations: ALS, amyotrophic lateral sclerosis; GENEVA, Genes and Environmental 
Exposures in Veterans with Amyotrophic Lateral Sclerosis study; PLS, primary lateral sclerosis. 


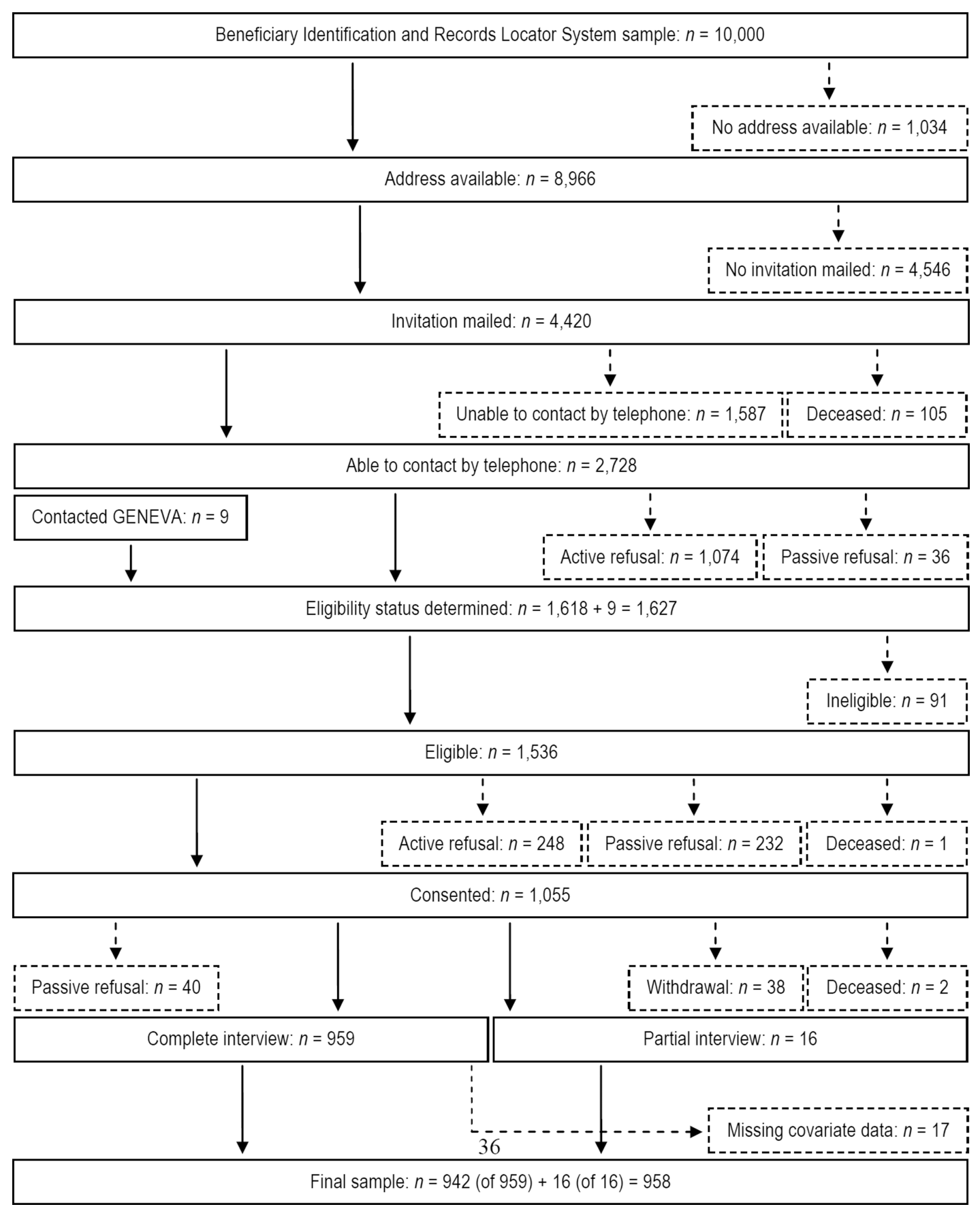

Figure 2.

Flow diagram depicting the ascertainment of GENEVA controls. Solid boxes or lines represent potential controls who advanced past each step shown. Small-dashed boxes or lines represent potential controls who were excluded after each step shown, but who were incorporated into the analysis via inverse probability weights (see Section 2.3 and Supplementary data, p. S6, for more details). Reasons potential controls were ineligible for GENEVA included not being a U.S. military veteran $(n=13)$, ALS or other neurological disease diagnosis (Schmidt et al., 2008) $(n=32)$, or other reasons $(n=46)$. Abbreviations: 
GENEVA, Genes and Environmental Exposures in Veterans with Amyotrophic Lateral Sclerosis study. 


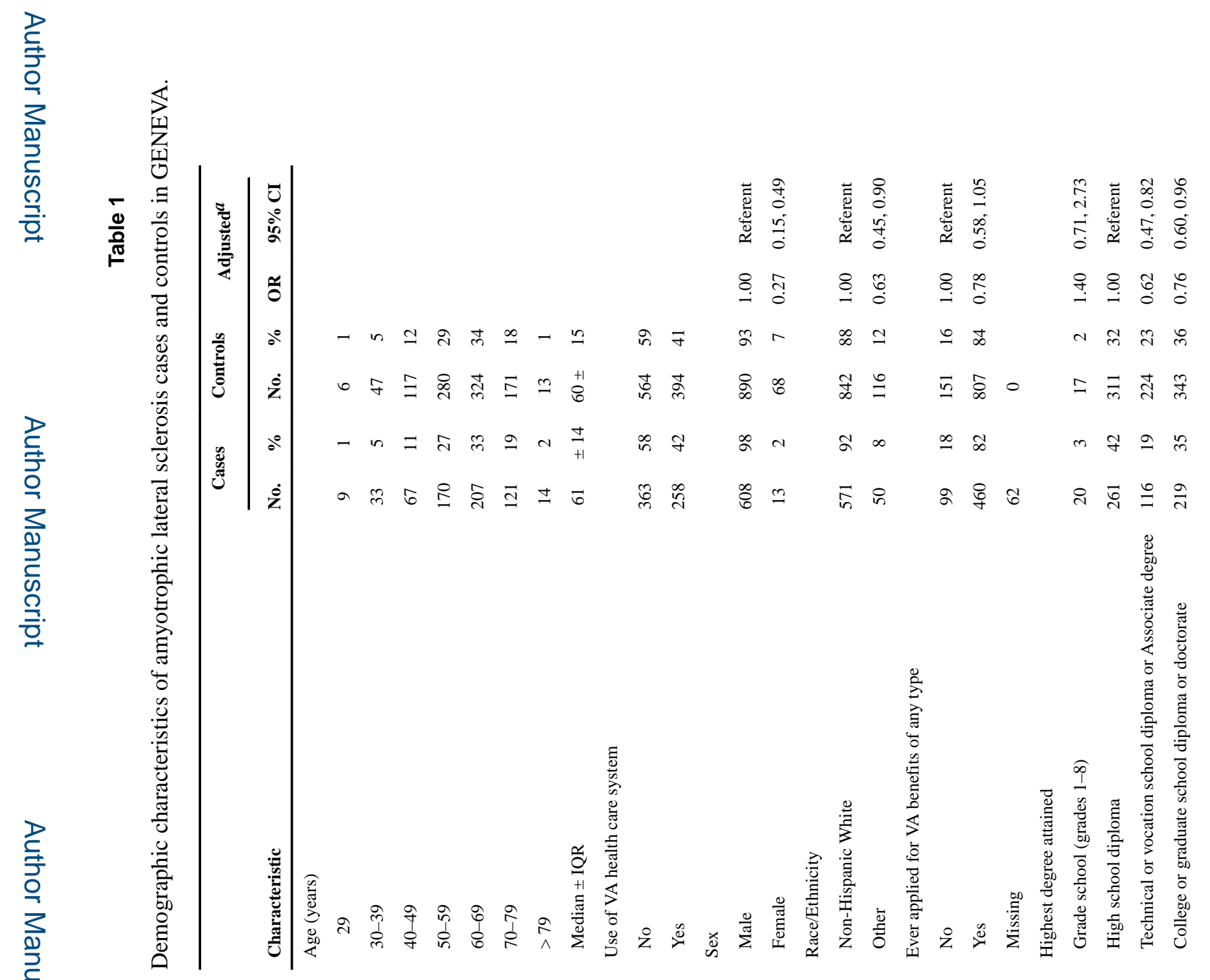


Beard et al.

Page 24

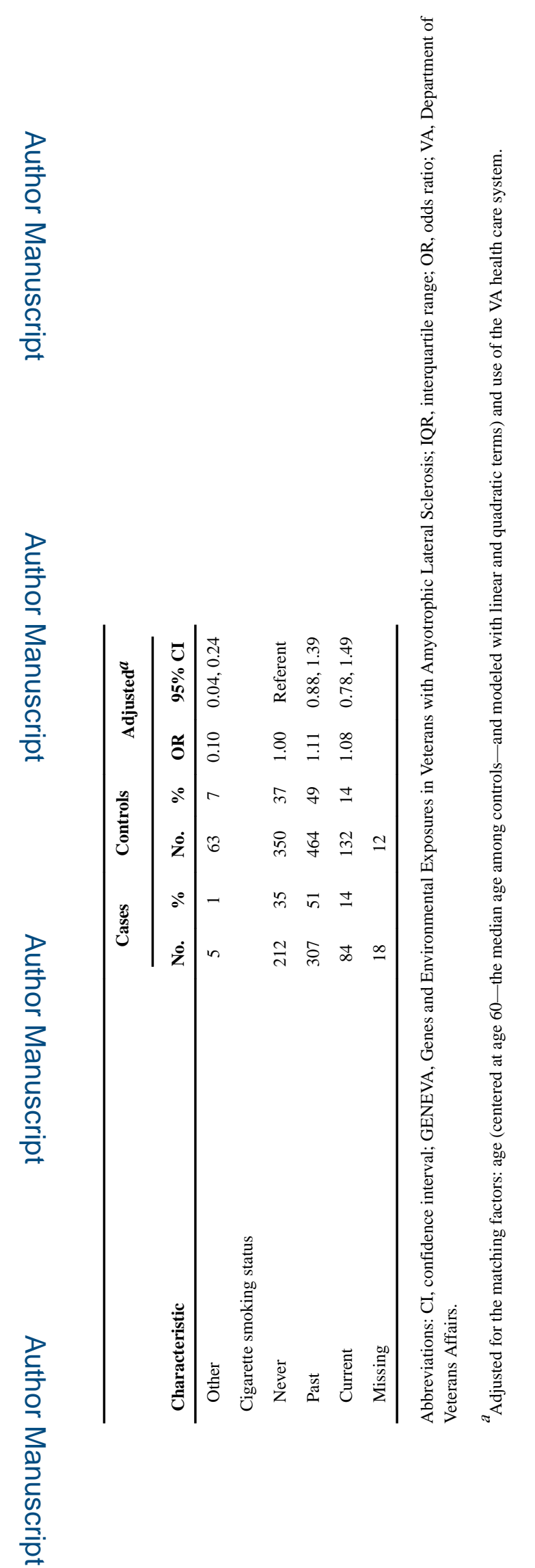

Environ Int. Author manuscript; available in PMC 2017 May 01. 
Table 2

Clinical characteristics of amyotrophic lateral sclerosis cases in GENEVA.

\begin{tabular}{|c|c|c|}
\hline Characteristic & No. & $\%$ \\
\hline \multicolumn{3}{|l|}{ Most recent ALS diagnosis category } \\
\hline Clinically definite & 148 & 24 \\
\hline Clinically probable & 314 & 51 \\
\hline Clinically possible & 48 & 8 \\
\hline Suspected (progressive bulbar palsy or progressive muscular atrophy) & 111 & 18 \\
\hline \multicolumn{3}{|l|}{ Symptom onset site } \\
\hline Bulbar & 89 & 14 \\
\hline Extremities & 500 & 81 \\
\hline Other $^{a}$ & 31 & 5 \\
\hline Missing & 1 & \\
\hline \multicolumn{3}{|l|}{ Time from symptom onset to diagnosis (months) } \\
\hline$\leq 6$ & 117 & 19 \\
\hline$>6-12$ & 168 & 28 \\
\hline$>12-18$ & 102 & 17 \\
\hline$>18-24$ & 46 & 8 \\
\hline$>24$ & 170 & 28 \\
\hline Missing & 18 & \\
\hline Median $\pm \mathrm{IQR}$ & $13 \pm$ & \\
\hline \multicolumn{3}{|l|}{ Time from diagnosis to enrollment in the Registry (months) } \\
\hline$\leq 12$ & 218 & 35 \\
\hline$>12-24$ & 142 & 23 \\
\hline$>24-36$ & 73 & 12 \\
\hline$>36-48$ & 43 & 7 \\
\hline$>48$ & 139 & 23 \\
\hline Missing & 6 & \\
\hline Median \pm IQR & $18 \pm$ & 32 \\
\hline \multicolumn{3}{|l|}{ Time from enrollment in the Registry to enrollment in GENEVA (months) } \\
\hline$\leq 6$ & 180 & 29 \\
\hline$>6-12$ & 205 & 33 \\
\hline$>12-18$ & 97 & 16 \\
\hline$>18-24$ & 74 & 12 \\
\hline$>24$ & 65 & 10 \\
\hline Median $\pm \mathrm{IQR}$ & $9 \pm$ & \\
\hline \multicolumn{3}{|l|}{ Baseline ${ }^{b}$ ALSFRS-R score (possible range: $\left.0-48\right)^{c}$} \\
\hline$\leq 16$ & 135 & 22 \\
\hline$>16-23$ & 118 & 19 \\
\hline$>23-30$ & 137 & 22 \\
\hline$>30-35$ & 110 & 18 \\
\hline$>35$ & 121 & 19 \\
\hline
\end{tabular}




\begin{tabular}{lcc}
\hline Characteristic & No. & $\%$ \\
\hline Median \pm IQR & $27 \pm 16$ \\
Currently using riluzole (baseline & $b$ ) & \\
No & 301 & 50 \\
Yes & 304 & 50 \\
Missing & 16 & \\
\hline
\end{tabular}

Abbreviations: ALS, amyotrophic lateral sclerosis; ALSFRS-R, ALS Functional Rating Scale-Revised; GENEVA, Genes and Environmental Exposures in Veterans with Amyotrophic Lateral Sclerosis; IQR, interquartile range.

ancludes "all over" $\left(\mathrm{n}<5^{d}\right)$, “cramps/fasciculations" $(\mathrm{n}=26)$, and "loss of appetite" $\left(\mathrm{n}<5^{d}\right)$.

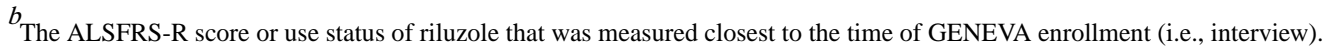

${ }^{c}$ Category boundaries were set at quintiles of the ALSFRS-R score among all cases.

${ }^{d}$ Suppressed to preserve the confidentiality of study participants. 


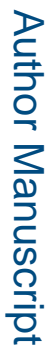

I

$\infty$
$\frac{0}{0}$
$\frac{0}{\oplus}$

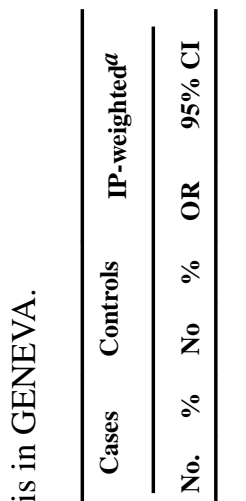

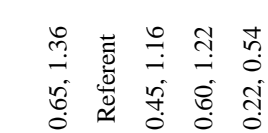

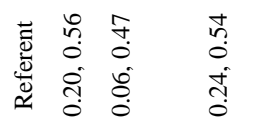

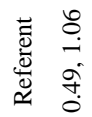

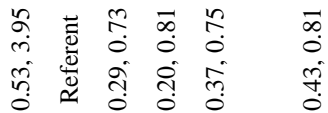

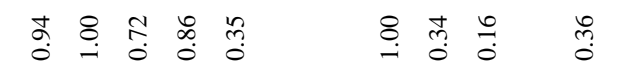

8.

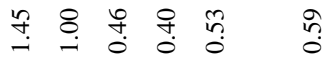

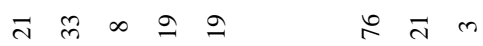

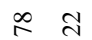

ก ๆ $2+8$

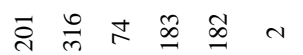

กิ๊

$\stackrel{\frac{1}{4}}{\stackrel{4}{N}}$

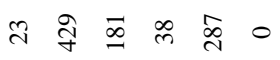

$\overline{4} \forall a d r$

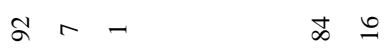

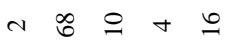

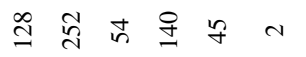

in 700

ㅎํㅇ $\mathrm{C}$

$n \frac{\infty}{\gamma}$ 的这

룰
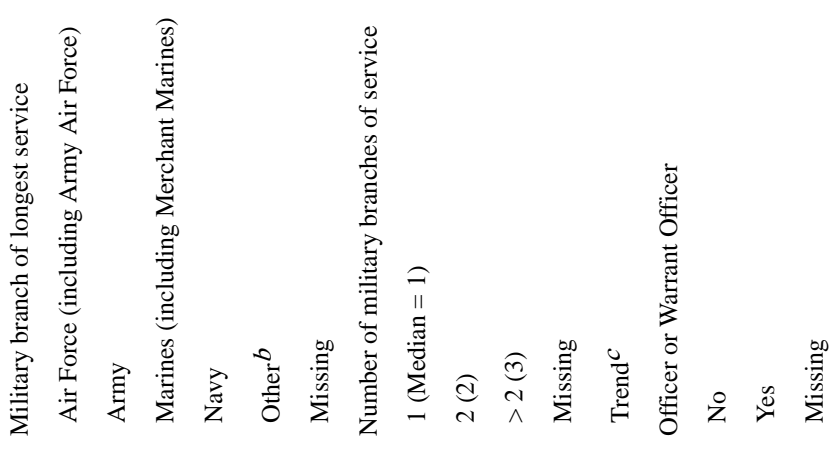

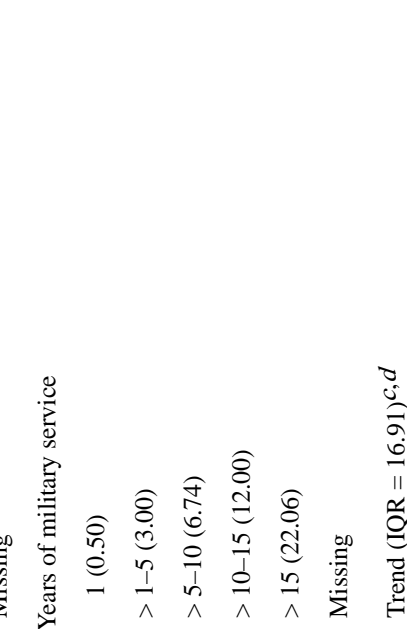

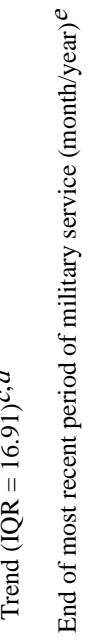

Environ Int. Author manuscript; available in PMC 2017 May 01. 


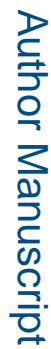

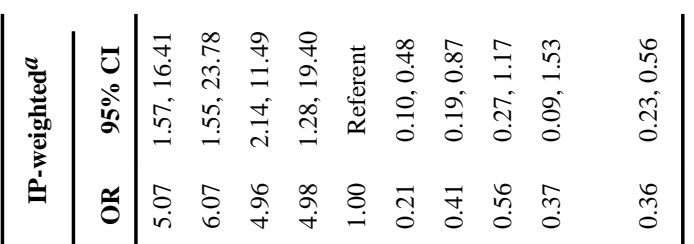

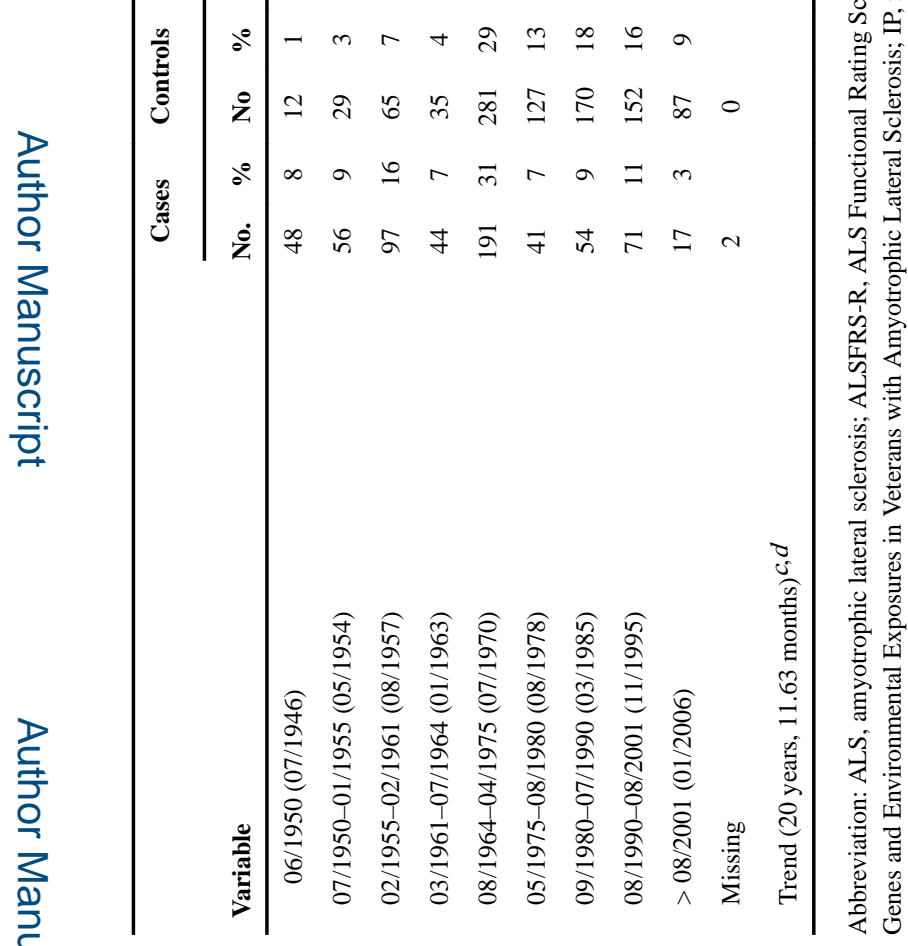

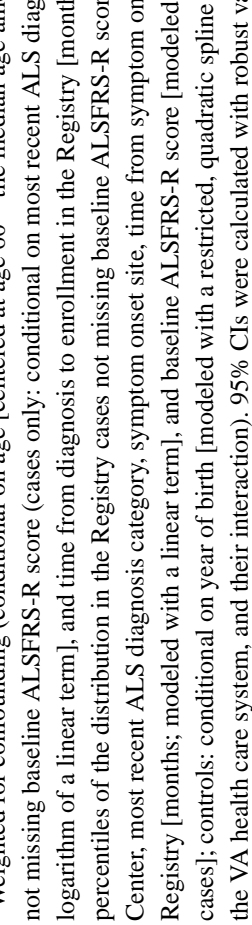

옴. 


\section{롤 \\ 골}

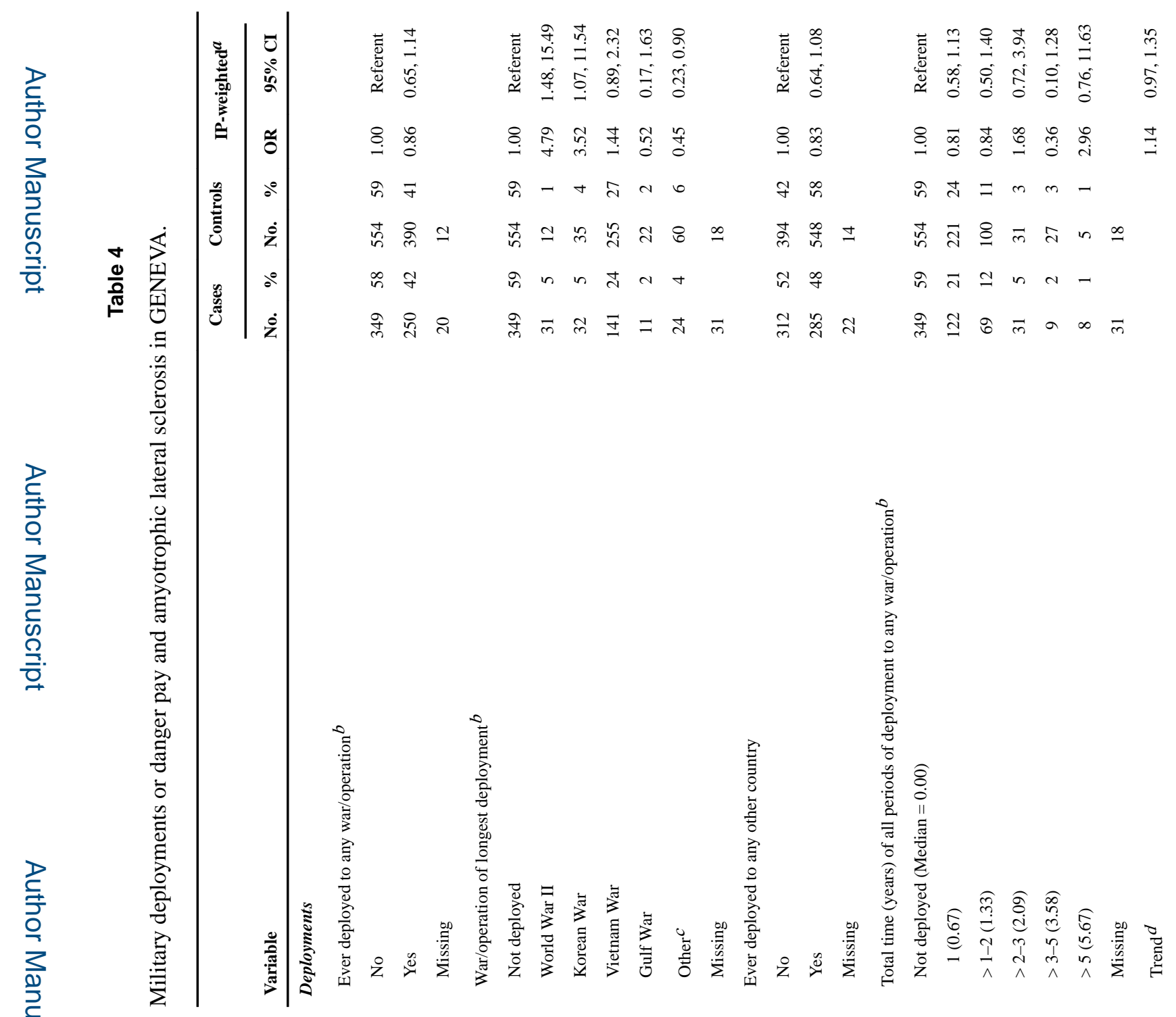

Environ Int. Author manuscript; available in PMC 2017 May 01. 


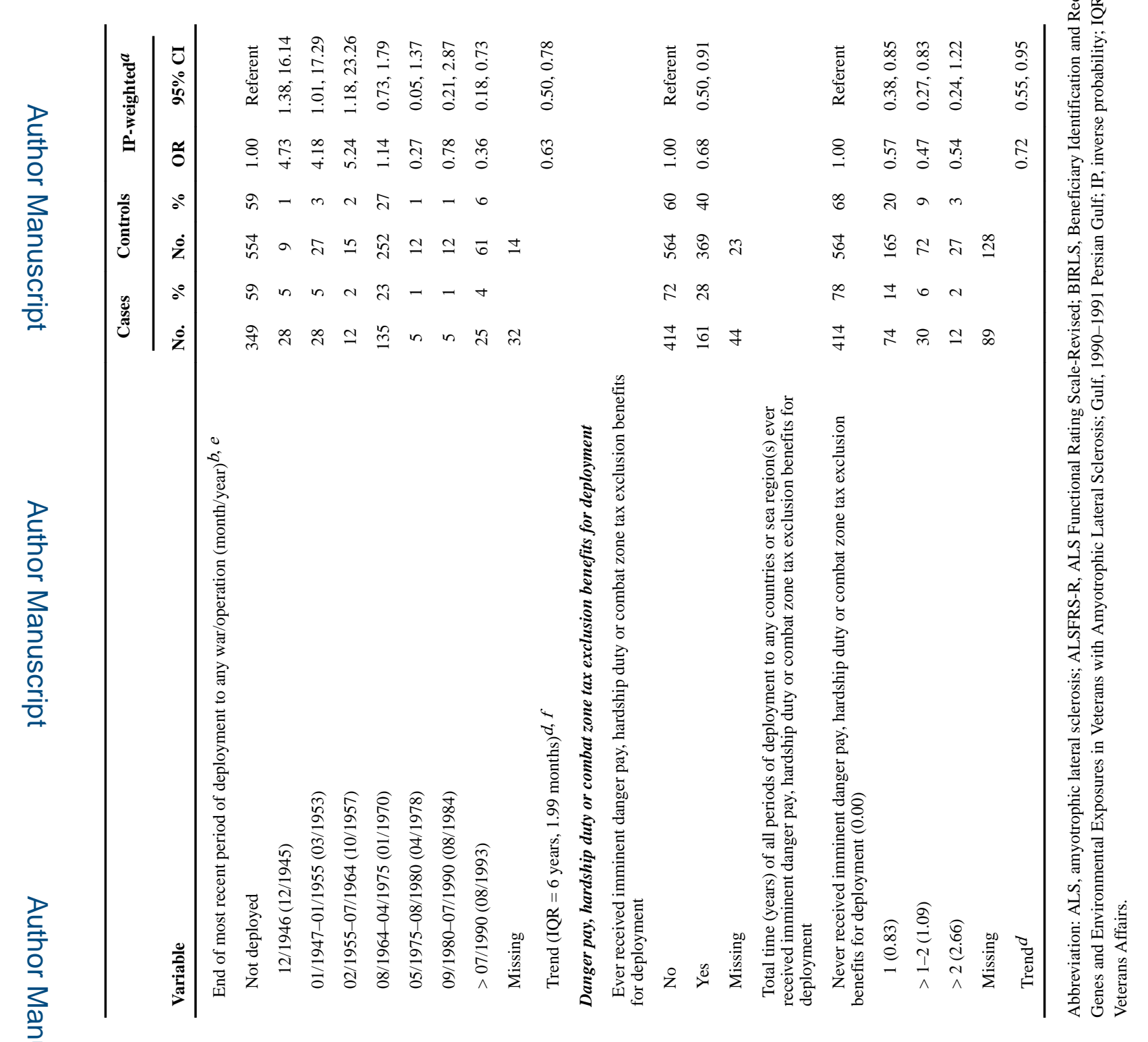


Beard et al.

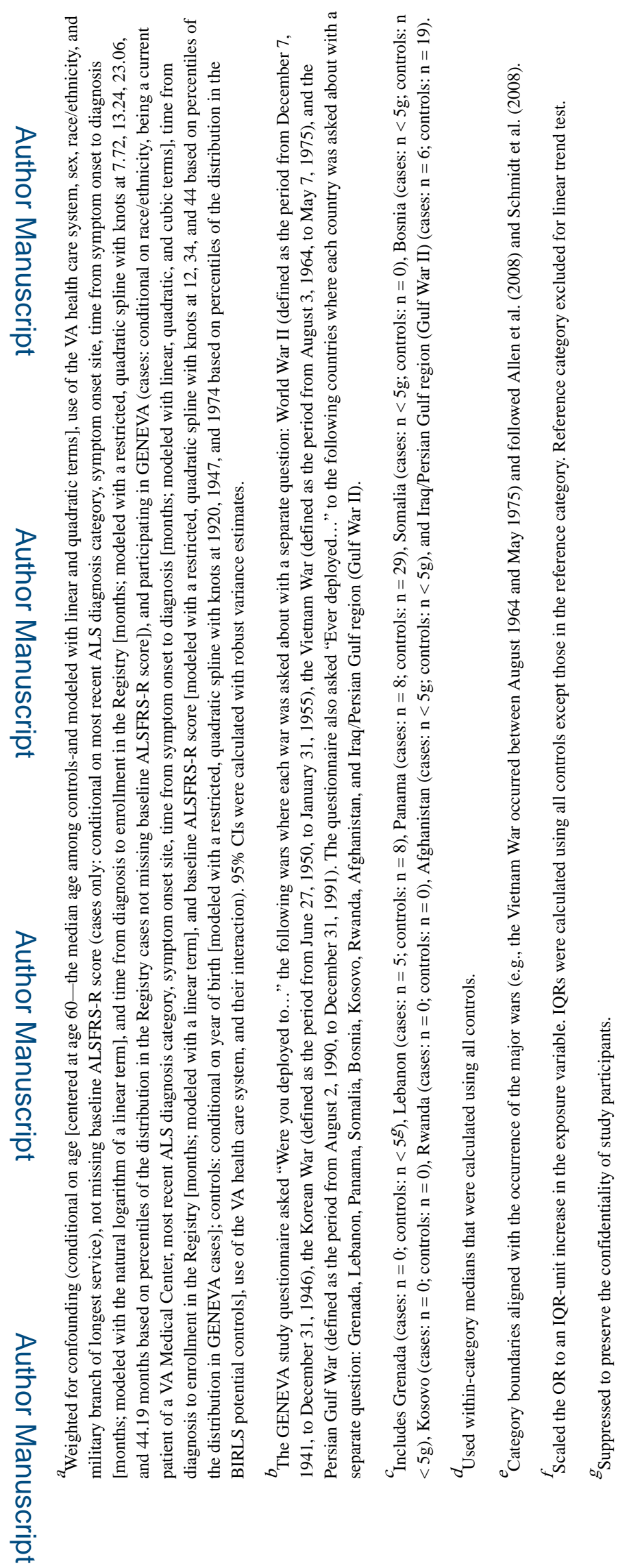

Environ Int. Author manuscript; available in PMC 2017 May 01. 


\section{올 \\ 골}



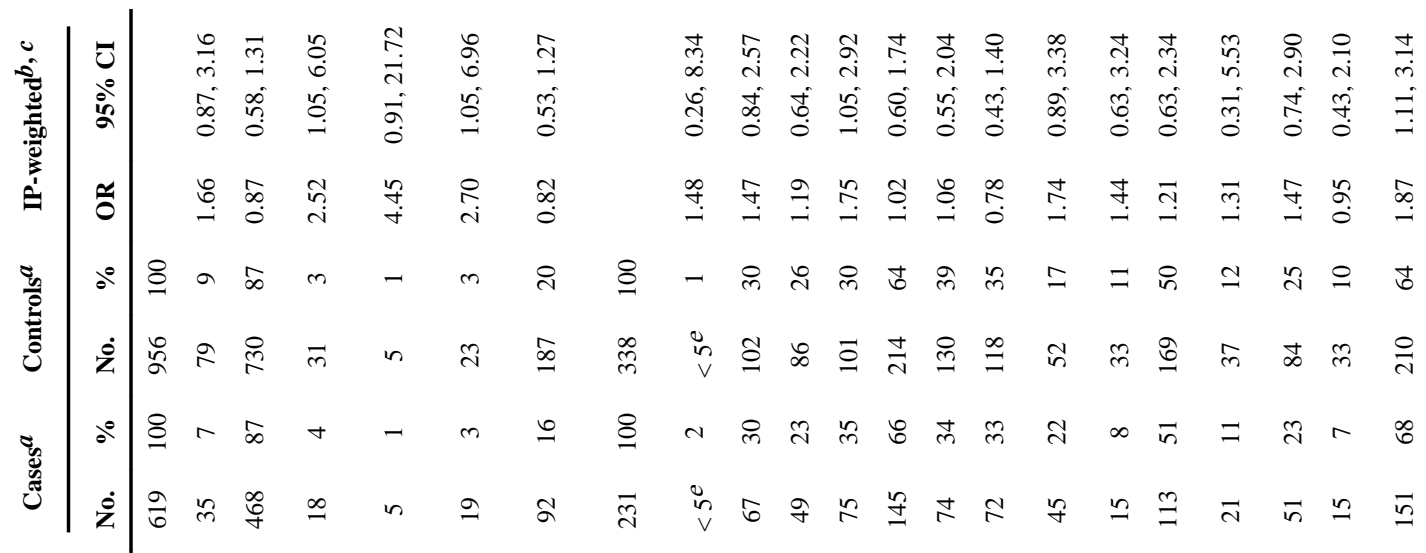

ग

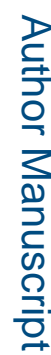

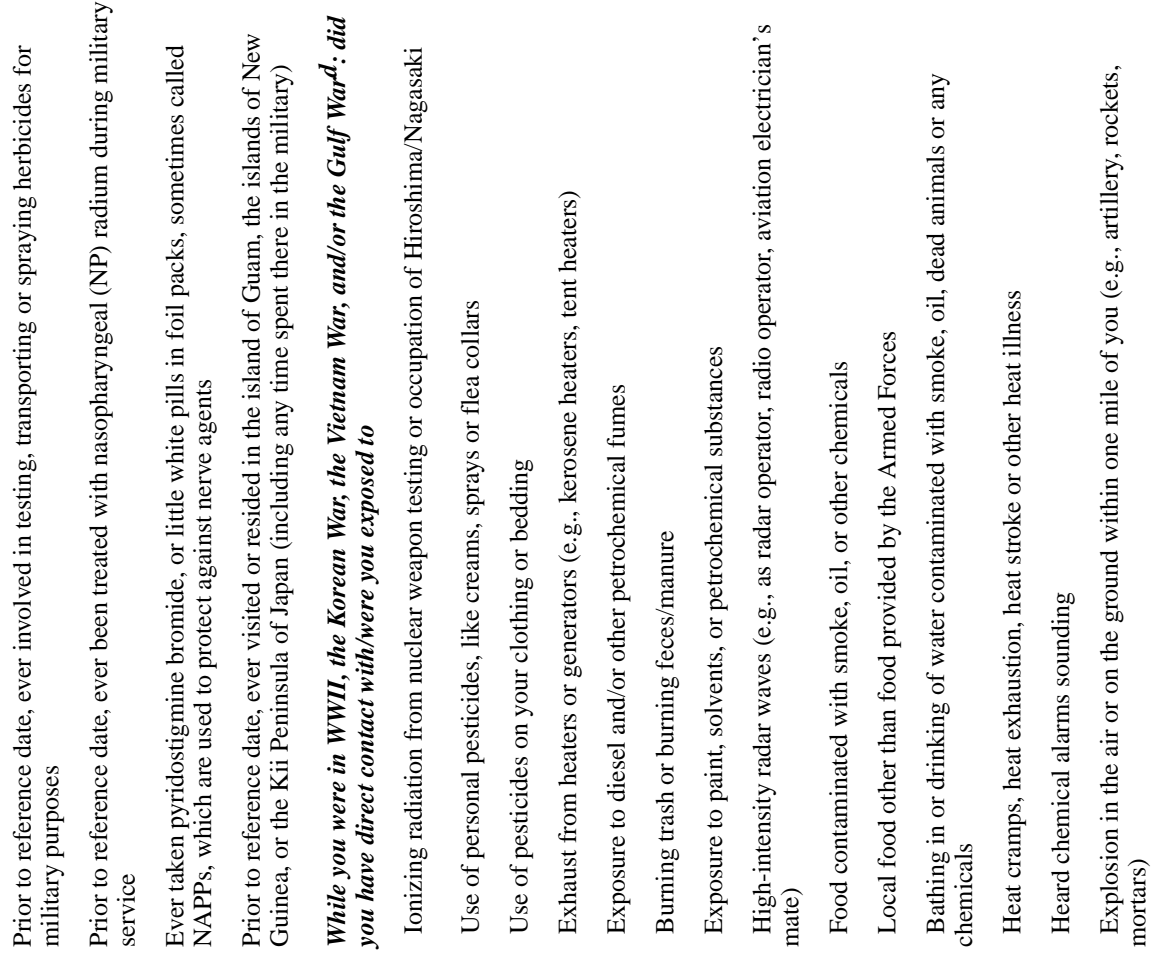

Environ Int. Author manuscript; available in PMC 2017 May 01. 


\section{롤 \\ 일}

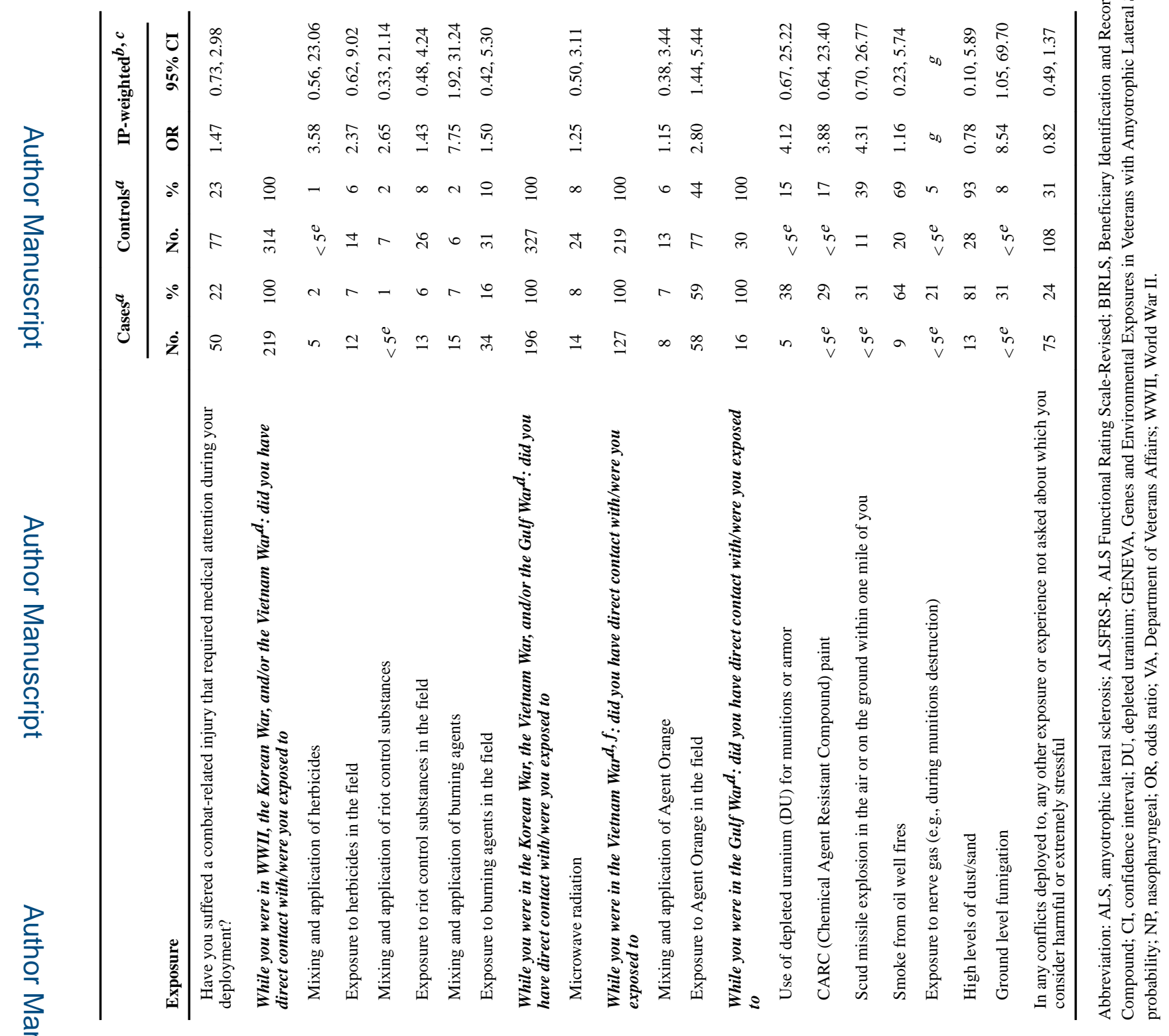




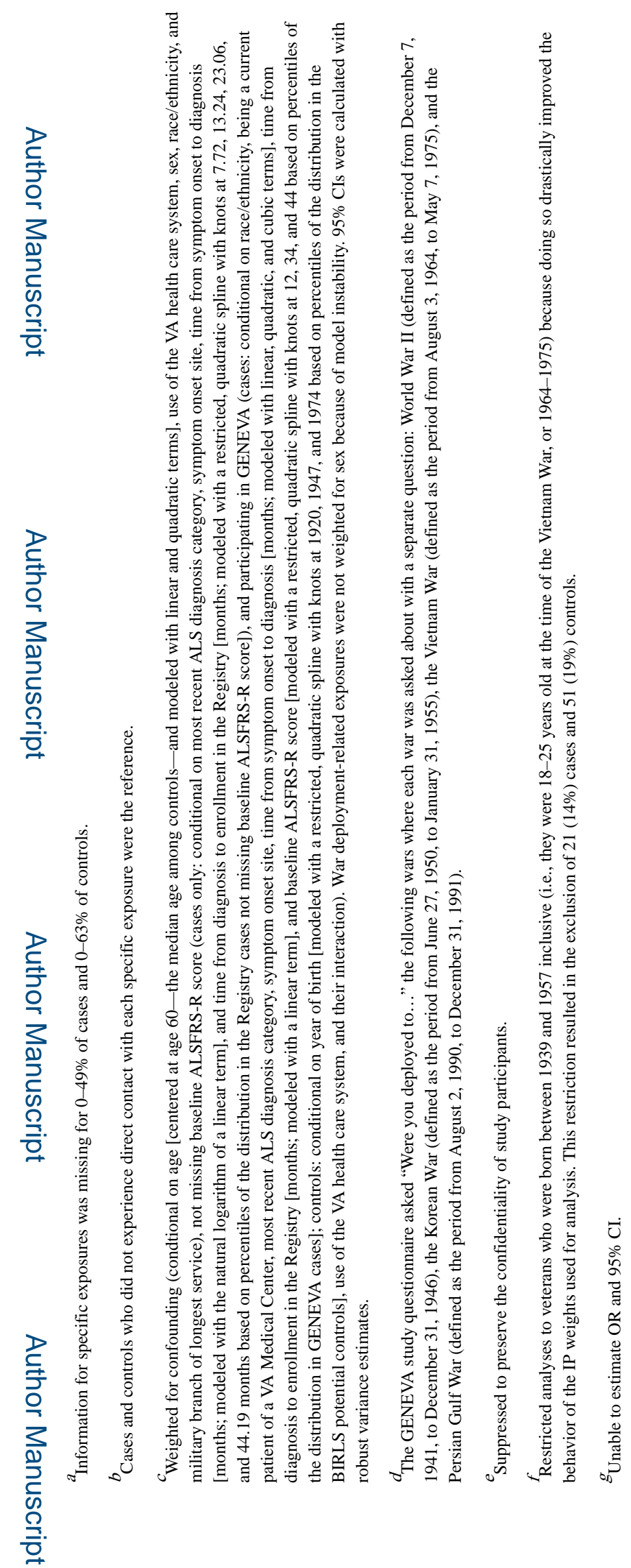

Environ Int. Author manuscript; available in PMC 2017 May 01. 